\title{
Biosimilar switching - current state of knowledge
}

\author{
Piotr Wiland ${ }^{1}$, Bogdan Batko², Marek Brzosko ${ }^{3}$, Eugeniusz J. Kucharz ${ }^{4}$, Włodzimierz Samborski ${ }^{5}$, \\ Jerzy Świerkot ${ }^{1}$, Ewa Więsik-Szewczyk ${ }^{6}$, Julia Feldman ${ }^{7}$
}

${ }^{1}$ Department of Rheumatology and Internal Medicine, Wrocław Medical University, Jan Mikulicz-Radecki University Teaching Hospital in Wrocław, Poland

${ }^{2}$ Rheumatology Unit, Józef Dietl Specialist Hospital in Kraków, Poland

${ }^{3}$ Department of Rheumatology, Internal Medicine and Geriatrics, Pomeranian Medical University in Szczecin, Poland

${ }^{4}$ Department of Internal Medicine and Rheumatology, Medical University of Silesia in Katowice, Poland

${ }^{5}$ Department of Rheumatology and Rehabilitation, Wiktor Dega Orthopaedic and Rehabilitation Teaching Hospital, University of Medical Sciences in Poznań, Poland

${ }^{6}$ Department of Internal Medicine, Pneumonology, Allergology and Clinical Immunology, Military Institute of Medicine in Warsaw, Poland

${ }^{7}$ Sandoz, Warsaw, Poland

\begin{abstract}
Evidence from over 10 years of clinical experience demonstrates that biosimilar medicines approved in the European Union can be used for all their registered indications as safely as their originators and with no negative impact on therapeutic efficacy. The debate on the use of biosimilars in rheumatology focuses specifically on the safety of switching between biosimilars and reference products. Studies conducted to date, including randomised double-blind and open-label extension trials, have not demonstrated any significant differences in therapeutic efficacy or safety between patients switched from one medicine to another and those who were continued on a single medicine. According to the latest recommendations for the use of biosimilars in rheumatic diseases, developed by an international task force in 2017, there is no clinical evidence that a single switch from an originator to a biosimilar medicine is associated with any significant risk for patient safety or reduction in therapeutic efficacy.
\end{abstract}

Key words: biosimilar medicine, switching, safety rheumatic diseases.

\section{Introduction}

The first biosimilar product was approved in Europe over 10 years ago, in 2006. It was a recombinant human growth hormone, somatropin, which proved effective in the treatment of growth disorders in children with growth hormone deficiency [1]. The approval of biosimilars in the European Union (EU) became possible after the European Medicines Agency (EMA) introduced a new approval pathway for biosimilars in 2004 [2]. Since 2006, Europe has approved the largest number of biosimilars worldwide. As a result, European countries have over 10 years of experience in the use of these medicinal products [2].
A biosimilar is a biological medicinal product with efficacy and safety comparable to the reference biologic. It contains the same active substance and is introduced to the market when the reference product is no longer under patent protection [3]. In accordance with strict EMA requirements, the biosimilarity of an authorised biosimilar medicine in terms of its molecular structure, biological activity, efficacy, and safety is confirmed by the results of comprehensive comparative studies [4]. Evidence from over 10 years of clinical experience demonstrates that biosimilar medicines approved in the EU can be used for all their registered indications as safely and efficaciously as their reference biologics [2]. 
Biosimilars are now broadly used in various fields of medicine. The first biosimilar to treat chronic inflammatory conditions, particularly in the field of rheumatology, was infliximab (CT-P13), a monoclonal antibody belonging to the group of tumour necrosis factor (TNF) inhibitors [4]. In the EU, there are currently 15 biosimilar medicinal products in 15 EMA procedures (4 active substances) approved for use in rheumatic diseases, and their number has been constantly increasing. Nine of these products contain a TNF inhibitor (data as of 17 May 2018) [5]. The list of currently approved biosimilars according to the EMA website is presented in Table I.

Biosimilars are currently widely discussed in the literature. Experts are particularly interested in the safety of switching between a biosimilar and its reference biologic. The aim of this paper was to present the current state of knowledge on biosimilar switching, with special focus on the results of clinical trials as well as registries of patients with rheumatic diseases receiving biological treatment.

\section{Interchangeability - switching or substitution?}

A guide to biosimilar medicines published by the EMA and European Commission in 2017 defines three terms related to biosimilar switching: interchangeability, switching and automatic substitution [2]. Interchangeability is a general term referring to the possibility of exchanging one medicinal product for another that is expected to produce the same clinical effect. Interchangeability encompasses both switching of the

Table I. Biosimilars currently approved for use in rheumatic diseases in the European Union. Based on the European Medicines Agency website [5]

\begin{tabular}{|c|c|c|c|c|}
\hline $\begin{array}{l}\text { Active } \\
\text { substance }\end{array}$ & Product name and doses & EMA procedure number & Authorisation holder & $\begin{array}{c}\text { Authorisation } \\
\text { date }\end{array}$ \\
\hline $\begin{array}{l}\text { Adalimumab } \\
\text { (ABP501) }\end{array}$ & $\begin{array}{c}\text { Amgevita } \\
(20 \mathrm{mg}, 40 \mathrm{mg})\end{array}$ & EMEA/H/C/004212 & Amgen Europe B.V. & $22 / 03 / 2017$ \\
\hline $\begin{array}{l}\text { Adalimumab } \\
\text { (ABP501) }\end{array}$ & $\begin{array}{c}\text { Solymbic } \\
(20 \mathrm{mg}, 40 \mathrm{mg})\end{array}$ & EMEA/H/C/004373 & Amgen Europe B.V. & 22/03/2017 \\
\hline $\begin{array}{l}\text { Adalimumab } \\
\text { (BI695501) }\end{array}$ & $\begin{array}{l}\text { Cyltezo } \\
(40 \mathrm{mg})\end{array}$ & EMEA/H/C/004319 & $\begin{array}{c}\text { Boehringer Ingelheim Interna- } \\
\text { tional } \mathrm{GmbH}\end{array}$ & $10 / 11 / 2017$ \\
\hline $\begin{array}{l}\text { Adalimumab } \\
\text { (SB5) }\end{array}$ & $\begin{array}{l}\text { Imraldi } \\
(40 \mathrm{mg})\end{array}$ & EMEA/H/C/004279 & $\begin{array}{c}\text { Samsung Bioepis UK Limited } \\
\text { /.../ }\end{array}$ & 24/08/2017 \\
\hline $\begin{array}{l}\text { Etanercept } \\
\text { (SB4) }\end{array}$ & $\begin{array}{c}\text { Benepali } \\
(25 \mathrm{mg}, 50 \mathrm{mg})\end{array}$ & EMEA/H/C/004007 & $\begin{array}{c}\text { Samsung Bioepis UK Limited } \\
/ \ldots /\end{array}$ & $14 / 01 / 2016$ \\
\hline $\begin{array}{l}\text { Etanercept } \\
\text { (GP2015) }\end{array}$ & $\begin{array}{c}\text { Erelzi } \\
(25 \mathrm{mg}, 50 \mathrm{mg})\end{array}$ & EMEA/H/C/004192 & Sandoz GmbH & 23/06/2017 \\
\hline $\begin{array}{l}\text { Infliximab } \\
\text { (SB2) }\end{array}$ & $\begin{array}{l}\text { Flixabi } \\
(100 \mathrm{mg})\end{array}$ & EMEA/H/C/004020 & $\begin{array}{c}\text { Samsung Bioepis UK Limited } \\
\text { /.../ }\end{array}$ & 26/05/2016 \\
\hline $\begin{array}{l}\text { Infliximab } \\
\text { (CT-P13) }\end{array}$ & $\begin{array}{l}\text { Inflectra } \\
(100 \mathrm{mg})\end{array}$ & EMEA/H/C/002778 & Hospira UK Limited & $10 / 09 / 2013$ \\
\hline $\begin{array}{l}\text { Infliximab } \\
\text { (CT-P13) }\end{array}$ & $\begin{array}{l}\text { Remsima } \\
(100 \mathrm{mg})\end{array}$ & EMEA/H/C/002576 & $\begin{array}{l}\text { Celltrion Healthcare Hungary } \\
\text { Kft. }\end{array}$ & $10 / 09 / 2013$ \\
\hline $\begin{array}{l}\text { Rituximab } \\
\text { (CT-P10) }\end{array}$ & $\begin{array}{l}\text { Ritemvia } \\
(500 \mathrm{mg})\end{array}$ & EMEA/H/C/004725 & $\begin{array}{l}\text { Celltrion Healthcare Hungary } \\
\text { Kft. }\end{array}$ & 13/07/2017 \\
\hline $\begin{array}{l}\text { Rituximab } \\
\text { (CT-P10) }\end{array}$ & $\begin{array}{l}\text { Rituzena } \\
(500 \mathrm{mg})\end{array}$ & EMEA/H/C/004724 & $\begin{array}{c}\text { Celltrion Healthcare Hungary } \\
\text { Kft. }\end{array}$ & $13 / 07 / 2017$ \\
\hline $\begin{array}{l}\text { Rituximab } \\
\text { (GP2013) }\end{array}$ & $\begin{array}{c}\text { Rixathon } \\
\text { (100 mg, } 500 \mathrm{mg})\end{array}$ & EMEA/H/C/003903 & Sandoz GmbH & $15 / 06 / 2017$ \\
\hline $\begin{array}{l}\text { Rituximab } \\
\text { (GP2013) }\end{array}$ & $\begin{array}{c}\text { Riximyo } \\
(100 \mathrm{mg}, 500 \mathrm{mg})\end{array}$ & EMEA/H/C/004729 & Sandoz GmbH & $15 / 06 / 2017$ \\
\hline $\begin{array}{l}\text { Rituximab } \\
\text { (CT-P10) }\end{array}$ & $\begin{array}{c}\text { Truxima } \\
(100 \mathrm{mg}, 500 \mathrm{mg})\end{array}$ & EMEA/H/C/004112 & $\begin{array}{l}\text { Celltrion Healthcare Hungary } \\
\text { Kft. }\end{array}$ & $17 / 02 / 2017$ \\
\hline $\begin{array}{l}\text { Rituximab } \\
\text { (CT-P10) }\end{array}$ & $\begin{array}{l}\text { Blitzima } \\
(500 \mathrm{mg})\end{array}$ & EMEA/H/C/004723 & $\begin{array}{c}\text { Celltrion Healthcare Hungary } \\
\text { Kft. }\end{array}$ & $13 / 07 / 2017$ \\
\hline
\end{tabular}


product (when the prescriber decides to exchange one medicine for another) and substitution (when the exchange occurs at the pharmacy level without consultation with the prescriber). While the EMA defines the terminology referring to interchangeability of biosimilar products, it does not provide regulations. Interchangeability practices are regulated by national regulatory authorities [2]. The EMA provides access to scientific data on biosimilars, but it does not issue recommendations on drug interchangeability. According to EMA experts, the decision on drug switching should involve the health care provided in consultation with the patient and should comply with local regulations on the use of biological products.

In 2015, the Dutch Medicines Evaluation Board issued the following statement on interchangeability of biosimilar products: "Biosimilars have been proven to have no relevant differences compared to an innovator biological medicine as far as quality, safety and efficacy are concerned." Moreover, the agency claimed that "the exchange between biological medicines is permitted, but only if adequate clinical monitoring is performed and the patient is properly informed" [6]. In the same year, the Finnish Medicines Agency published the following position statement: "biosimilars are interchangeable with their reference products under the supervision of a health care person" [7]. Thus, individual national regulatory authorities basically support switching between biologics (but not automatic substitution) provided that the patient is monitored and is involved in shared therapeutic decision making. Shared decision making is also emphasized by the 2017 recommendations developed by the Task Force on the Use of Biosimilars to Treat Rheumatological Diseases, including 25 experts from 8 countries [8].

In this context, it is interesting to discuss the draft guidance for industry on the criteria for full interchangeability (including automatic substitution) of a biological medicine, developed by the US Food and Drug Agency [9]. Apart from pharmacovigilance (which is required also in EU countries), the agency may require that drug manufacturers perform at least one randomised clinical trial comparing patients who undergo multiple treatment switches (at least 3) with those continued on the same treatment. Most randomised trials conducted to date involved only one treatment switch. In this context, it is worth citing a phase III EGALITY trial with a biosimilar of etanercept, GP2015 [10], which randomized patients to continue the same treatment with the originator or to undergo a sequence of three switches between the originator and the biosimilar. The study, described in detail below, did not show a negative effect of switching on therapy safety or efficacy.

\section{Biosimilarity - a new concept in biotechnology?}

The development of a biosimilar medicine is based on comprehensive head-to-head studies that compare biosimilars with their originators to demonstrate significant similarity of molecules in terms of structure, biological activity, pharmacodynamic and pharmacokinetic parameters, as well as efficacy, safety, and immunogenicity [2]. For the biosimilar medicine to be approved, its biosimilarity has to be demonstrated based on the full body of evidence from all phases of drug development. It is also required to allow safe switching between the biosimilar and reference medicines and to ensure the same clinical effect of the drug.

Studies on biosimilarity are based on the comparability concept, which has been used for decades to ensure the similarity of the same reference drug before and after a manufacturing change [11]. Changes are inherent to the drug manufacturing process and have been observed on the market for a long time. If a change in the manufacturing process has occurred, the manufacturing company should provide the EMA with documentation that confirms the comparability of molecules before and after the change. This is required for the medicinal product to stay on the market and remain available for patients. The medicinal products before and after the change are not identical but rather comparable [11, 12]. From the perspective of the health care provider and the patient, this means that the change has had no significant impact on the efficacy or safety of the product. The medicinal products before and after the manufacturing change approved by the EMA can always be switched [12]. It can also be assumed that each patient on long-term biological treatment is likely to have received more than one similar version of the same reference biologic [12].

Because biologics are derived from living organisms, their variability is also determined by the natural variability of proteins (referred to as "microvariability"), the same as observed in human proteins. Such minor variability can be present within a single batch or between different batches of the same biological medicine [2]. The acceptable range of variability for the biosimilar medicine is the same as the acceptable range of batch-tobatch variability of the reference medicine [2], while the strict control measures ensure that the minor variability does not affect the safety or efficacy of the product.

From the regulatory and scientific perspective, the biosimilar and its reference medicine are only different versions of the same active substance [11]. It is believed that the approved biosimilar product with high similarity to the reference medicine may be even considered the same biological medicine as a new batch of the origina- 
tor product [8]. The biosimilarity of a biosimilar product should be confirmed in comparative studies in the same way as comparability of a reference drug before and after a manufacturing change is confirmed [11, 12].

\section{Immunogenicity of biologics and biosimilars}

One of the important issues in the discussion on biosimilar medicines is their immunogenicity. It is known that all biological medicines may induce an immune response and that monoclonal antibodies or fusion proteins are structurally ideal antigens. Immunogenicity that develops during therapy may affect its efficacy and result in adverse effects. The effect of anti-drug antibodies depends on their activity (neutralising vs. non-neutralising, transient vs. persistent) and titres, among other factors.

A systematic review of the immunogenicity of biologics in chronic inflammatory diseases (rheumatoid arthritis - RA, psoriatic arthritis - PsA, juvenile idiopathic arthritis, ankylosing spondylitis - AS, non-radiographic axial spondyloarthritis, psoriasis, Crohn's disease - CD, and ulcerative colitis - UC) included 433 of over 21,000 publications [13]. It revealed that all analysed biologics (including adalimumab, reference infliximab and its biosimilar CT-P13, etanercept, certolizumab, and rituximab) have a similar level of immunogenicity. An exception was etanercept, a fusion protein whose lower immunogenicity may be associated with its molecular structure as well as the route and frequency of administration.

Factors that may affect immunogenicity include active inflammatory disease, which involves immune system mobilisation, as well as increased need for medication and a fast reduction of its blood concentration. The results of clinical trials show that the anti-drug antibody titre increases during the first 28 weeks of biological treatment $[14,15]$. Another important factor is the concomitant use of methotrexate, which was shown to reduce the immunogenicity of a biologic agent in RA [13]. Finally, immunogenicity of a biologic agent may be increased by long interruptions in therapy, which lead to a reduction in its blood concentration [13].

\section{Effect of switching on therapeutic efficacy and safety - clinical experience}

There is growing experience with the use of biosimilars, including biosimilar switching. The first available data on the safety of switching concerned mainly simple biopharmaceuticals such as erythropoietins. However, there have been an increasing number of reports on switching between complex proteins, such as monoclonal antibodies or fusion proteins.
In 2012, a review of switching studies was published, [16] which included 13 crossover studies on recombinant human growth hormone ( $\mathrm{rGGH}$ ) products, 35 crossover studies on erythropoietin products, and 10 crossover studies on granulocyte-colony stimulating factor (G-CSF) products. The authors found no evidence that switching between biological medicines (including switches between biologics and their biosimilars) adversely affected therapy safety.

In their reviews, Lopez-Siguero et al. [17] and Borras-Perez et al. [18] summarised 10 years of experience with the use of biosimilar $\mathrm{rhGH}$ and reported that switches between the reference product or another rh$\mathrm{GH}$-containing product and the biosimilar did not affect therapeutic efficacy or safety. They analysed the results of phase III and IV trials, as well as those of an ongoing post-approval study in patients with growth disorders in the course of growth hormone deficiency or small for gestational age.

Other interesting results come from the post-approval, randomised, double-blind PIONEER study, which analysed the efficacy and safety of a filgrastim biosimilar, EP2006, in the prevention of severe neutropenia in patients with breast cancer receiving myelosuppressive chemotherapy [19]. Participants were randomised to four arms: two arms received only one product (biosimilar or originator) and the two other arms received alternating treatments during each successive chemotherapy cycle, that is, the biosimilar then the originator, and vice versa. The treatment switch did not increase the risk of developing antibodies against recombinant human G-CSF. No significant differences were also observed in terms of therapeutic efficacy (prevention of severe neutropenia) or safety in the alternating and non-alternating groups [19].

Multiple treatment switches were also investigated in the multicentre, randomised, double-blind EGALITY trial [10]. This phase III confirmatory study in patients with moderate to severe chronic plaque psoriasis aimed to compare the efficacy and safety of the etanercept biosimilar GP2015 and the originator product [10]. The study assessed the effect of three treatment switches, at 6-week intervals, on efficacy, safety, and immunogenicity $[10,20]$. The results showed that triple switching had no effect on efficacy, as measured by the Psoriasis Area and Severity Index (PASI) scores: PASI 50, PASI 75, and PASI 90 [10, 20]. Moreover, the incidence of treatment emergent adverse events (TEAEs) was comparable between groups, which confirmed similar safety profiles. During the study only 6 patients revealed transient presence of low titres of non-neutralising anti-drug antibodies ( 5 patients during the first 4 weeks of treatment and 1 patient at week 36 ). During the second phase of 
treatment, which involved three switches, none of the patients showed the presence of anti-drug antibodies, confirming low immunogenic potential of the biosimilar and originator products [10].

The NOR-SWITCH study [21] was a phase IV non-inferiority randomised trial assessing the effect of switching on the results of biological therapy in immune-mediated inflammatory diseases including RA, PSA, AS, plaque psoriasis, UC, and CD. The study assessed the efficacy and safety of switching from infliximab originator to the biosimilar CT-P13, in comparison with continued treatment with infliximab originator. Patients on stable treatment with the originator for at least 6 months before randomisation were eligible. Of the 481 patients, 241 were on continued treatment and 240 were switched from the originator to CT-P13. In 78\% of the patients, the originator was their first biologic agent. Simultaneous immunosuppressive treatment was administered in $47 \%$ and $54 \%$ of the infliximab originator group and CT-P13 group, respectively.

The primary endpoint in the NOR-SWITCH study [21] was defined as disease worsening during 52-week follow-up, with the assumed non-inferiority margin of $15 \%$. Disease worsening was defined separately for each condition, but the study did not have sufficient power to demonstrate non-inferiority for each individual disease [21]. In the per-protocol analysis set, disease worsening occurred in 53 patients (26\%) on continued treatment and in 61 patients (30\%) of the CT-P13 group. The 95\% $\mathrm{Cl}$ for the adjusted treatment difference $(-4.4 \%)$ ranged from $-12.7 \%$ to $3.9 \%$, which matched the pre-defined non-inferiority margin. The frequency of adverse events (AEs, including serious AEs - SAEs) was similar between groups, and switching was not shown to affect immunogenicity. The NOR-SWITCH study was the first randomised trial to reveal that switching from the originator to the biosimilar TNF inhibitor does not result in worse outcomes than continued therapy with the originator (with the assumed non-inferiority margin of 15\%) [21].

Prior to the NOR-SWITCH study, other large international multicentre randomised confirmatory studies of the infliximab biosimilar CT-P13 were conducted: PLANETRA and PLANETAS $[14,15]$. The randomised double-blind phase III PLANETRA study in patients with RA demonstrated comparable efficacy of the biosimilar CT-P13 and the reference infliximab product (including assessment of radiographic progression), immunogenicity, and pharmacokinetics during 54-week follow-up. The safety profiles of CT-P13 and the originator were also similar [15]. The PLANETAS study in patients with AS reported similar results [14]. Both studies had a 1-year open-label extension phase, which analysed two groups of patients: one group on continued treatment with the infliximab bio- similar CT-P13 and the other group that was switched from the reference infliximab to the biosimilar product $[22,23]$. The aim of the extension study was to compare the efficacy and safety of switching from the reference product to CT-P13 vs. continuing CT-P13 treatment.

In the PLANETRA extension study, the American College of Rheumatology (ACR) response rates were comparable between the maintenance and switch groups: $71.8 \%$ and $71.8 \%$, respectively, for ACR20, $48 \%$ and $51.4 \%$, respectively, for ACR50, and $24.3 \%$ and $26.1 \%$, respectively, for ACR70. The percentage of patients with anti-drug antibodies at the end of the study was comparable: $40.3 \%$ in the maintenance group and $44.8 \%$ in the switch group. TEAEs occurred in a similar proportion of patients in the two groups (53.5\% vs. 53.8\%) [22]. The PLANETAS extension study was the first to demonstrate that switching from the reference infliximab to its biosimilar CT-P13 in patients with AS has no adverse effect on therapeutic efficacy or safety [23].

Other interesting data come from the Danish DANBIO registry, which analysed the effect of switching from originator to biosimilar infliximab on disease activity and frequency of exacerbations in patients with RA, PSA, and axial spondyloarthritis. Disease activity was assessed 3 months before and after the switch [24]. In most patients, disease activity was similar before and after the switch. The frequency of exacerbations was also comparable between the two time points.

The most extensive body of evidence on the safety of switching comes from studies on biosimilar infliximab, because it has been on the market longer than other biosimilar TNF inhibitors [14, 15, 21-24]. However, there are also some first data available on the safety of switches with biosimilar etanercept (GP2015, SB4) and adalimumab (ABP501) [10, 20, 25-27].

In an open-label extension study comparing the efficacy and safety of the etanercept reference product and its biosimilar SB4 in patients with RA, patients were divided into two groups: the first one continuing SB4 therapy and the other switched from the reference product to SB4 [25]. The efficacy of therapy was comparable between groups $(77.9 \%$ and $79.1 \%$ of patients with ACR20 response in the maintenance and switch groups, respectively). Safety endpoints were also comparable (percentage of patients with TEAEs: $47.6 \%$ in the maintenance group and $48.7 \%$ in the switch group). Efficacy and safety were comparable between the SB4/ SB4 and reference etanercept/SB4 groups, showing no risk associated with switching patients from reference to biosimilar etanercept.

In 2017, the results of a multicentre randomised double-blind phase III study comparing the efficacy, safety, and immunogenicity of the adalimumab biosim- 
ilar ABP501 with the reference product in patients with moderate to severe plaque psoriasis were published [26]. The study included one treatment switch from the reference to the biosimilar product. Similar clinical efficacy, safety, and immunogenicity of both products were demonstrated during 52-week follow-up. A single switch from the originator to its biosimilar ABP501 did not affect the clinical outcome of treatment. Moots et al. [27] reviewed studies that investigated switching between the reference biologics infliximab, etanercept, adalimumab, and rituximab and their biosimilars. The authors identified 53 studies (published and unpublished) in rheumatology, gastroenterology and dermatology, including 38 completed studies. They emphasized that the effects of switching can be assessed in clinical trials and real-world studies. Such studies can provide high-quality evidence on switching provided they apply proper methodology and design. Of the 38 completed studies, 5 were phase III or IV randomised double-blind clinical trials, 6 were open-label extension studies, and 1 was a confirmatory study. The remaining studies included, for example, retrospective open-label or single-centre non-randomised studies, yet the number of those studies provide additional data for the discussion on the safety of switches. The authors emphasised that studies conducted so far have not shown meaningful differences in efficacy or safety between switching vs. continued therapy [27]. They concluded that further evidence is needed on long-term post-switch efficacy, safety, and immunogenicity of biosimilars. Moreover, the decision on switching to a biosimilar should be made on a case-bycase basis and supported by available scientific data [27]

A more detailed analysis shows that the results of open-label studies may differ from those of randomised double-blind studies, and the differences may be explained by the nocebo effect (defined as the opposite of the placebo effect). The nocebo effect results from negative expectations of the patient concerning therapy, which may lead to subjective health complaints (i.e. symptoms perceptible only by the patient) and therapy discontinuation [28]. One of the subjective health complaints in RA, PSA, or AS is excessive pain [29]. The Dutch multicentre prospective BIO-SWITCH study in patients with RA, PSA, and AS investigated switching from originator infliximab to the biosimilar CT-P13. Its primary endpoint was defined as a change in disease activity after 6 months, measured with the Disease Activity Score in 28 joints using the C-reactive protein (CRP) level (DAS28-CRP) in patients with RA and PsA and the Bath Ankylosing Spondylitis Disease Activity Index (BASDAI) in patients with AS [29]. The secondary endpoints were CRP levels, erythrocyte sedimentation rate, serum infliximab concentration, and safety including the incidence of AEs and SAEs. Reasons for therapy discontinuation were also recorded, with a distinction according to objective measurements (e.g. swollen joint count, abnormal laboratory findings) and subjective health complaints (i.e., descriptive terms for symptoms perceptible only by the patient), such as joint pain, fatigue, and headache.

In total, 47 of the 197 patients discontinued CT-P13 therapy due to a perceived lack of effect $(n=26)$, AEs $(n=11)$, or a combination thereof $(n=10)$, which constituted $24 \%$ of the patients switched from the reference to the biosimilar product. Most cases of therapy discontinuation were associated with an increase in tender joint count and the patient's global assessment of disease activity and/or in subjective AEs. According to the authors, 25 of 32 AEs (78\%) could be classified as subjective health complaints [29].

The authors compared their safety results with the results of the randomised double-blind NOR-SWITCH study. Both studies reported a similar incidence of SAEs (5\% vs. 9\%, respectively), infections (respiratory tract infections: $2 \%$ vs. $4 \%$ ), and infusion-related reactions ( $0.5 \%$ vs. $2 \%$ ). However, the percentage of patients who discontinued treatment due to AEs (11\% vs. 3\%) and the frequency of subjective health complaints (e.g. joint pain: $41 \%$ vs. $3 \%$ ) were higher in the BIO-SWITCH study. These results show that the rate of therapy discontinuation may be higher in open-label studies than in randomised studies due to more commonly reported subjective AEs and the nocebo effect [29]. The authors of the BIO-SWITCH study concluded that the only method to improve therapy acceptance and persistence rates after switching to a biosimilar product is to optimise the way in which switching is communicated to the patient. It is also important to educate rheumatologists and pharmacists about the nocebo effects and types of symptoms that may be subjective health complaints [29].

The importance of the therapeutic relationship and communication between a patient and his or her health care provider is also emphasized in the latest consensus-based recommendations for the use of biosimilars to treat rheumatological diseases [8]. Both the treating health care provider and the patient should be fully aware of any switch and should agree with its implementation. The importance of educating patients about the nature of biosimilars and their rigorous approval and development process is also emphasized. Patients should be informed that the approved biosimilar can be considered essentially the same biologic as a new batch of the reference product, that it has a comparable safety profile to the reference product, and that treatment should yield similar therapeutic benefits [8]. Finally, patients should be educated about the economic benefits of switching, as availability of biosimilars should greatly 
expand access of patients to otherwise expensive biological treatments.

According to the recommendations, there is evidence confirming the safety of switching to biosimilars in the treatment of rheumatic diseases [8]. The evidence shows that a single switch from an originator to a biosimilar product is safe and effective. There is currently no evidence that switching between biosimilars of the same reference product may produce a different clinical effect [8]. However, it is important to consider the patient's perspective as well as analysing new scientific data from open-label studies on new biosimilars, as they may offer additional information from larger populations than those included in randomised trials. It is recommended that multiple switches between biosimilars and reference products or other biosimilars should be assessed in registries [8]. The available evidence on the safety of multiple switches is still limited, although the first results have already been reported from a phase III trial on the use of the etanercept biosimilar GP2015 in moderate to severe plaque psoriasis [10, 20].

Automatic substitution from the reference to the biosimilar product or vice versa may be associated with a lack of awareness about potential AEs or inefficacy of the newly introduced product. For example, in the NOR-SWITCH study one of the inclusion criteria was a stable outcome of treatment with the originator product in the 6 months preceding enrolment. It is also advisable to assess the effect of the previous therapy on disease activity before switching to a new product, or to switch directly after scheduled treatment monitoring tests, for example after 6 or 12 months according to prescription drug programmes in Poland.

Importantly, since January 2011, new medicines approved for use in the EU are labelled as being under "additional monitoring" [5]. They have a black inverted triangle displayed in their package leaflet and in the summary of product characteristics. All marketed medicines are monitored, but medicines with the black triangle are monitored more intensively [5]. This is typically because there is less information on a given medicine than on other medicines, for example because it is new to the market. However, it does not mean that the medicine is unsafe. The "additional monitoring" label is used to encourage health care providers to report AEs, especially those suspected to be caused by the administered medicine. This may help collect more information on the new medicines. The list of medicinal products under additional monitoring, which is regularly updated, is available at the EMA website: http://www.ema.europa.eu/ docs/en_GB/document_library/Medicines_under_additional_monitoring/2013/04/WC500142453.pdf.
The list includes medicinal products registered according to the centralised or national procedure if they meet one of the following criteria: a) the medicine contains a new active substance not present in any other medicinal product authorised in the EU before 1 January $2011, b)$ the medicine is a biological medicine (either biosimilar or originator) authorised in the EU after 1 January 2011, c) the company that markets the medicine is required to carry out a post-authorisation safety study, and d) the medicine has been given a conditional approval [5]. The list contains both biologics and selected synthetic medicines. The medicines with the black inverted triangle are both originators and biosimilars. The list includes the name of the medicinal product, the name of its active substance, the reason for inclusion in the list, the name of the marketing authorisation holder, a link to product information, and the date of inclusion in the list.

\section{Conclusions}

The use of biosimilars in patients naïve to biological therapy does not raise any doubts among experts. Evidence from clinical trials and increasing experience from daily clinical practice confirm that biosimilars are equivalent to reference products in terms of quality, efficacy, and safety profile, including also extrapolated indications. Switching clinically stable patients from originator biologics to their biosimilar alternative still raises concerns among some health care providers, although according to available clinical trials and literature reviews a single switch from an originator to a biosimilar is not associated with any significant risk or loss of efficacy [30]. There is also no evidence that switching between biosimilars of the same reference product produces a different clinical effect, as emphasized by the recommendations for the use of biosimilars to treat rheumatological diseases [8]. Because clinical evidence on the safety of multiple switches is scarce, patient monitoring in registry and long-term observational studies is recommended to provide more data [8].The above recommendations also emphasize the need for careful monitoring of patient after a treatment switch. The type of the medicinal product used should be clearly identified in medical records. According to the EU legislation, all new biologics, including biosimilars, are closely monitored after being introduced to the market, specifically in terms of reporting any suspected AEs related to the use of a given product [5]. The black inverted triangle symbol is displayed in the summary of product characteristics of both biosimilar and originator medicines authorised and marketed after 1 January 2011 [5].

Finally, an important issue in the discussion on the safety of biosimilar switching is the involvement of both the health care provider and the patient in shared 
therapeutic decision-making. Kay et al. [8] recommend that both the patient and his or her health care provider should be aware of the therapeutic decisions. What is more, the patient should be informed about the nature of biosimilars, including the rigorous process of their approval and the available evidence on their quality, efficacy, and safety. The patient should also be educated that the introduction of biosimilars to the market has significantly reduced the costs of biological therapy, which may greatly increase its availability to a larger group of patients.

The article was developed in cooperation with Sandoz. The authors were Sandoz consultants and lecturers (SK/219/10-2017).

\section{References}

1. Summary of Product Characteristics Omnitrope, 2017; http:// www.ema.europa.eu/docs/pl_PL/document_library/EPAR_Product_Information/human/000607/WC500043695.pdf (accessed 12.12.2017).

2. Biosimilars in the EU. Information guide for healthcare professionals; EMA, EC 2017; http://www.ema.europa.eu/docs/ en_GB/document_library/Leaflet/2017/05/WC500226648.pdf (accessed 12.12.2017).

3. Kucharz EJ, Stajszczyk M, Batko B, et al. Biopodobne leki biologiczne w reumatologii. Forum Reumatol 2017; 3: 191-204.

4. Dörner T, Kay J. Biosimilars in rheumatology: current perspectives and lessons learnt. Nat Rev Rheumatol 2015; 11: 713-724.

5. www.ema.europa.eu (accessed 17.05.2018).

6. https://english.cbg-meb.nl/ (accessed 10.01.2018).

7. https://www.fimea.fi/web/en/-/are-biosimilars-interchangeable- (accessed 10.01.2018).

8. Kay J, Schoels MM, Dörner T, et al. Consensus-based recommendations for the use of biosimilars to treat rheumatological diseases. Ann Rheum Dis 2018; 77: 165-174.

9. Considerations in Demonstrating Interchangeability With a Reference Product. Guidance for industry. Draft guidance. 2017; https://www.fda.gov/downloads/Drugs/GuidanceComplianceRegulatoryInformation/Guidances/UCM537135.pdf (accessed 11.01.2018).

10. Griffiths CE, Thaçi D, Gerdes S, et al. The EGALITY study: a confirmatory, randomized, double-blind study comparing the efficacy, safety and immunogenicity of GP2015, a proposed etanercept biosimilar, vs. the originator product in patients with moderate-to-severe chronic plaque-type psoriasis. $\mathrm{Br}$ J Dermatol 2017; 176: 928-938.

11. Kurki P, van Aerts L, Wolff-Holz E, et al. Interchangeability of biosimilars: A European perspective. BioDrugs 2017; 31: 83-91.

12. McCamish M, Woollett GR. Molecular Sameness Is Key Guiding Principle for Extrapolation to Multiple Indications. Clin Pharmacol Ther 2017; 101: 603-605.

13. Strandt V, Balsa A, Al-Saleh J, et al. Immunogenicity of Biologics in Chronic Inflammatory Diseases: A Systematic Review. BioDrugs 2017; 31: 299-316.
14. Park W, Yoo DH, Jaworski J, et al. Comparable long-term efficacy, as assessed by patient-reported outcomes, safety and pharmacokinetics, of CT-P13 and reference infliximab in patients with ankylosing spondylitis: 54 weeks results from the randomized, parallel-group PLANETAS study. Arthritis Res Ther 2016; 18: 25.

15. Yoo DH, Racewicz A, Brzezicki J, et al. A phase III randomized study to evaluate the efficacy and safety of CT-P13 compared with reference infliximab in patients with active rheumatoid arthritis: 54 week results from PLANETRA study. Arthritis Res Ther 2016; 18: 82.

16. Ebbers HC, Muenzberg M, Schellekens H. The safety of switching between therapeutic proteins. Expert Opin Biol Ther 2012; 12: $1473-1485$

17. Lopez-Siguero JP, Pfaffle R, Chanson P, et al. Ten years' clinical experience with biosimilar human growth hormone: a review of efficacy data. Drug Des Devel Ther 2017; 11: 1489-1495.

18. Borras-Perez MV, Kristrom B, Romer T, et al. Ten years' clinical experience with biosimilar human growth hormone: a review of safety data. Drug Des Devel Ther 2017; 11: 1497-1503.

19. Blackwell K, Semiglazov V, Krasnozhon D, et al. Comparison of EP2006, a filgrastim biosimilar, to the reference: a phase III, randomized, double-blind clinical study in the prevention of severe neutropenia in patient with breast cancer receiving myelosuppressive chemotherapy. Ann Oncol 2015; 26: 19481953.

20. Gerdes S, Thaci D, Griffiths CEM, et al. Multiple switches between GP2015, an etanercept biosimilar, with originator product do not impact efficacy, safety and immunogenicity in patients with chronic plaque type psoriasis: 30 weeks results from the phase 3, confirmatory study. J Eur Acad Dermatol Venereol 2018; 32: 420-427.

21. Jørgensen K, Olsen IC, Goll GL, et al. Switching from originator infliximab to biosimilar CT-P13 compared with maintained treatment with originator infliximab (NOR-SWITCH): a 52-week, randomised, double-blind, non-inferiority trial. Lancet 2017; 389: 2304-2316

22. Yoo DH, Prodanovic N, Jaworski J, et al. Efficacy and safety of CT-P13 (biosimilar infliximab) in patients with rheumatoid arthritis: comparison between switching from reference infliximab to CT-P13 and continuing CT-P13 in the PLANETRA extension study. Ann Rheum Dis 2017; 76: 355-363.

23. Park W, Yoo DH, Miranda P, et al. Efficacy and safety of switching from reference infliximab to CT-P13 compared with maintenance of CT-P13 in ankylosing spondylitis: 102-week data from the PLANETAS extension study. Ann Rheum Dis 2017; 76: 346-354.

24. Glintborg B, Sorensen IJ, Loft AG, et al. Nationwide non-medical switch from originator infliximab to biosimilar CT-P13 in 802 patients with inflammatory arthritis: 1 year clinical outcomes from the DANBIO study. Ann Rheum Dis 2017; 76: 14261431.

25. Emery P, Vencovsky J, Sylwestrzak A, et al, Long-term efficacy and safety in patients with rheumatoid arthritis continuing on SB4 or switching from reference etanercept to SB4. Ann Rheum Dis 2017; 76: 1986-1991.

26. Papp K, Bachelez H, Costanzo A, et al. Clinical similarity of biosimilar ABP 501 to adalimumab in the treatment of patients 
with moderate to severe plaque psoriasis: A randomized, double-blind, multicenter, phase III study. J Am Acad Dermato 2017; 76: 1093-1102.

27. Moots R, Azevedo V, Coindreau JL, et al. Switching Between Reference Biologics and Biosimilars for the Treatment of Rheumatology, Gastroenterology and Dermatology Inflammatory Conditions: Considerations of the Clinicians. Curr Rheumatol Rep 2017; 19: 37.

28. Petersen GL, Finnerup NB, Colloca L, et al. The magnitude of nocebo effects in pain: a meta-analysis. Pain 2014; 155: 1426 1434.
29. Tweehuysen L, van den Bemt, van Ingen IL, et al. Subjective Complaints as the Main Reason for Biosimilar Discontinuation after Open-Label Transitioning from Originator to Biosimilar Infliximab. Arthritis Rheumatol 2018; 70: 60-68.

30. Inotai A, Prins CP J, Csanadi $M$, et al. Is there a reason for concern or is it just a hype? A systematic literature review of the clinical consequences of switching from originator biologics to biosimilars. Expert Opin Biol Ther 2017; 17: 915-926. 